\title{
Análise da propaganda de medicamentos em TV aberta para o Distrito Federal e "Entorno"
}

\author{
Analysis of advertising of medication in open TV \\ for the Federal District and the surrounding cities
}

\author{
Fernando HONORATO \\ UniEvangelica - Centro universitário de Anápolis - GO. \\ Av. Universitária Km. 3,5 - Cidade Universitária \\ Anápolis - GO CEP: 75083-515.E-mail:fhnquimica@yahoo.com.br
}

\begin{abstract}
Advertising is a legitimate tool and not a problem if the commercial objectives do not exceed the ethical limits. Advertisements for medicines in Brazil were already produced since 1911 and promoted the sale of pharmaceuticals close to explicitly. However, medicines are special products whose advertisements require special care regarding the ethical and moral. To investigate and quantify what are the offenses committed in medicines advertisements published in Open TV for the general public of the Federal District and the surrounding cities, called "Surrounding Region", a descriptive, observational, cross-sectional study was carried on. Therefore, 56 advertisements were monitored at $14 \mathrm{~h}$ daily schedule, from March, 2012 to March 2013. The legal analysis was done under the aegis of Anvisa Board Resolution RDC. 96/2008. The results showed that 100\% from analysed advertisements presented violations of law. On average were infringed four articles of RDC by presentation and in total there were seven ignored articles of Health Legislation. Consistent with the literature, analgesics, cold medicine, anti-inflammatory and antacids were the most publicized. The absence of information on the care/warnings in use, characterized the medicine as completely safe and effective, which creates health risks of irresponsible self-medication, which is an important public health problem.
\end{abstract}

Key Words: medicine advertisement; Health surveillance; Substance-related disorders; self-medication

\section{RESUMO}

A publicidade é uma ferramenta legítima e não é um problema, se os objetivos comerciais não ultrapassarem os limites éticos. As propagandas de medicamentos no Brasil já eram produzidas desde 1911 e promoviam a venda de medicamentos "mais ou menos" explicitamente. Entretanto, medicamentos são produtos especiais, cujas peças publicitárias requerem cuidados diferenciados no que tange os aspectos éticos e morais. $\mathrm{O}$ estudo objetivou investigar quais são e quantificar os ilícitos cometidos em propagandas de medicamentos veiculadas em TV Aberta para o grande público do Distrito Federal e cidades que o circundam, chamadas "Região do Entorno". No estudo observacional, transversal e descritivo, foram monitoradas 56 propagandas, em 14h de programação, entre março de 2012 a março de 2013. A análise legal da monitoração de 40 peças incluídas na amostragem ocorreu sob a égide da Resolução de Diretoria Colegiada RDC No 96/2008 da Anvisa. Os resultados evidenciaram que em 100\% das peças publicitárias ocorreram infrações à legislação. Em média foram infringidos quatro artigos da RDC por propaganda e no total foram sete os artigos ignorados da Legislação Sanitária. Em consonância com a literatura, os analgésicos, antigripais, anti-inflamatórios e antiácidos foram os mais divulgados. A ausência de informação sobre os cuidados/advertências, no uso, pode indicar que o medicamento seja totalmente seguro e eficaz, o que induz ao risco sanitário da automedicação irresponsável, que tem se tornado um problema de saúde pública mundial

Palavras-Chave: Publicidade de medicamentos; Vigilância sanitária; Transtornos relacionados ao uso de substâncias; automedicação 


\section{INTRODUÇÃO}

A propaganda é uma ferramenta legítima, utilizada por instituições diversas na divulgação de produtos, conceitos e ideias $(1,2)$. Assim, pode-se afirmar que, a publicidade não é um problema, se os objetivos comerciais não ultrapassam os limites éticos (2).

As principais propagandas de medicamentos no Brasil tiveram início na década de 1980 e desde então, se constata um crescimento contínuo do número de peças publicitárias inseridas em diversos meios de comunicação, que também aumentaram muito em números e alcance desde aquela época (3).

De acordo com a Lei Federal ${ }^{0} 5.991$ de 17 de dezembro de 1973, que dispõe sobre o controle sanitário do comércio de fármacos, medicamentos, insumos farmacêuticos e correlatos, o medicamento é um "produto farmacêutico, tecnicamente obtido ou elaborado, com finalidades profiláticas, curativas, paliativas ou para fins de diagnóstico (4)". Destarte, são substâncias ou preparações, elaboradas em farmácias ou indústrias farmacêuticas, que atendem a especificações técnicas legais, para garantir a segurança dos consumidores e são semelhantes em todos os países (5).

Diferente dos medicamentos, os remédios possuem um conceito amplo, aplicado a iniciativas terapêuticas utilizadas no controle e combate a doenças ou sintomas: repouso, exercícios, entre outras terapias (5). Por conseguinte, medicamentos são produtos especiais, cujas peças publicitárias requerem cuidados diferenciados no que tange os aspectos éticos e morais (6). Nesse sentido, a "mercadoria" medicamento, nas formações sociais capitalistas, serve como uma das materializações ou símbolos da saúde (3).

Assim, a introdução dos medicamentos de venda livre no mercado facilitou a automedicação, pois sua aquisição não está sujeita à obrigatoriedade de prescrição médica, e não há nada que impeça sua aquisição (7). Estes medicamentos são reconhecidos pela legislação brasileira desde 1975, quando o seguimento foi regulamentado (3).

No Brasil pelo menos $35 \%$ dos medicamentos são adquiridos por automedicação, ou seja, para cada dois medicamentos prescritos, pelo menos um é consumido sem orientação médica, sendo comum a reutilização de receitas (8).

Na maioria dos países e no Brasil, os medicamentos se apresentam como o principal agente tóxico, em aproximadamente $26 \%$ dos casos de intoxicação humana que são registrados, anualmente, pelo Sistema Nacional de Informações Tóxico-farmacológicas - SINITOX/CICT/FIOCRUZ/MS (9). Os antigripais, analgésicos e anti-inflamatórios estão entre as classes de medicamentos que mais causam intoxicação no Brasil (9). No ano de 2010, o percentual se manteve em $26,9 \%$, ou seja, dos 17 agentes tóxicos monitorados, os medicamentos apresentam a maior incidência de toxicidade (9).

Com efeito, esses medicamentos de fácil acesso, são utilizados para tratar dores de cabeça, resfriados, cólicas, dores musculares, dentre outros problemas de saúde de menor gravidade e são eles os protagonistas do quadro de automedicação e intoxicação (1).

De acordo com a Organização das Nações Unidas (ONU), o uso abusivo de medicamentos é um problema mundial (1). Como exemplo, pode-se citar o paracetamol, que é de fácil aquisição e está presente na formulação de vários medicamentos e assim, a população o consome em grande quantidade e de modo inadvertido ou mesmo com intenções suicidas $(1,10)$.

Consequentemente, pode ocorrer intoxicação pelo seu uso em pouco tempo, de horas a até semanas após a ingestão da sobredose e levar o consumidor a um transplante hepático (1).

No Brasil, foram consumidos mais de $92 \mathrm{mi}$ lhões de comprimidos da marca "mais famosa" do analgésico ácido acetilsalicílico em 2009 (1). No planeta, são vendidos cerca de 216 milhões de comprimidos desse analgésico por dia (11). Nos Estados Unidos, são gastos 650 milhões de dólares a cada 12 meses com antiácidos (11).

Com essa noção de valores monetários, a propaganda de medicamentos ressalta principalmente, a eficácia, a segurança, o bem estar, a comodidade na administração, a rapidez da ação do medicamento, além do bom humor, da energia, do prazer e da felicidade que eles trazem $(11,15)$, minimizando ao máximo, ou simplesmente excluindo, qualquer referência a riscos, possíveis interações medicamentosas ou contra indicações (11).

Todas estas classes de medicamentos são isentos de prescrição médica (16).

Assim, sabendo o que é a medicalização (o impacto da propaganda no crescimento do consumo do medicamento), pois, na opinião dos entrevistados pelo PROCON de São Paulo em 2007, "a publicidade de medicamentos induz à automedicação $(63,33 \%)$ ", essa publicidade, apresenta a solução para todos os males, por meio de anúncios de TV, no rádio, em jornais revistas ou internet $(3,12)$.

Essas práticas se chocam com o que se preconiza nacional e internacionalmente no âmbito do uso correto, racional, consciente e seguro de medicamentos (13).

Com o objetivo precípuo de investigar quais são e quantificar os ilícitos cometidos em propagandas de medicamentos, assim como, avaliar o risco a que estão expostos os receptores desses comerciais, realizou-se o presente estudo $(14,15)$. 


\section{MATERIAL E MÉTODOS}

Trata-se de um estudo observacional, transversal e descritivo, no qual foram monitoradas e analisadas 56 peças publicitárias. Desta amostra, 16 peças foram desconsideradas e excluídas da pesquisa, quando se trataram de simples repetições, para se evitar a tendenciosidade no tratamento dos dados.

Para a realização da análise, cada propaganda distinta foi considerada sendo uma peça publicitária independente, considerou-se, para o tratamento de dados coletados e visualização adequada dos resultados a estatística descritiva.

Os dados das propagandas foram randomicamente coletados (mimetizando o comportamento de espectador ao assistir uma programação, em canal de TV aberta) no período de março de 2012 a março de 2013.

As observações geraram anotações sistematizadas, transcritas ipsis literis verbis, com as características a respeito de cada peça, após sua exposição em um dos canais de cinco (05) emissoras de TV aberta, que transmitem programação, no âmbito do Distrito Federal e cidades do estado de Goiás que a circundam.

Essas cidades formam uma região que é conhecida, em nível nacional, por; "região do Entorno".

Foi escolhida a "TV aberta" para a coleta de dados, pois, desde a década de 70 , a televisão já está consolidada como o meio de comunicação mais popular da história, com abrangência em praticamente todo o país (2).

As emissoras de TV foram identificadas por letras, a fim de se preservar seu anonimato e não lhes causar nenhum prejuízo, posto que, este não foi um dos objetivos deste trabalho. Nesta pesquisa, as emissoras de TV aberta, foram identificadas como; "B", "RT", "R", "G" e "S", em ordem crescente do número do canal.

Os medicamentos expostos nas peças publicitárias foram classificados de acordo com as classes terapêuticas nas quais estão inseridos (16). Os medicamentos que são compostos de mais de um princípio ativo foram classificados na classe terapêutica do princípio ativo principal.

A monitorização considerou as peças publicitárias apresentadas em 14 horas diárias de programação.

\section{RESULTADOS E DISCUSSÃO}

As peças publicitárias foram analisadas (análise legal) à luz da Resolução de Diretoria Colegiada no 96/ RDC/2008/ANVISA/SVS/MS (17), publicada em 17 de dezembro de 2008. Essa norma dispõe sobre a propaganda, publicidade, informação e outras práticas cujo objetivo seja a divulgação ou promoção comercial de medicamentos.
O objetivo inicial foi verificar o cumprimento dos artigos $22^{\circ}$, inciso VII, e $23^{\circ}$ caput e parágrafo único do título II, da resolução ${ }^{\circ}$ 96/RDC/2008/ANVISA/ SVS/ MS, que tratam dos: "Requisitos para a propaganda ou publicidade de medicamentos industrializados isentos de prescrição".

$\mathrm{O}$ artigo 22, inciso VII trata da obrigatoriedade da apresentação da seguinte advertência: "SE PERSISTIREM OS SINTOMAS, O MÉDICO DEVERÁ SER CONSULTADO".

No art. 23 é determinado no caput: “A propaganda ou publicidade de medicamentos isentos de prescrição médica deve também, veicular advertência relacionada à substância ativa do medicamento, conforme a tabela do anexo III".

No parágrafo único do artigo 23 é exigido que: "No caso de não ser contemplada alguma substância ativa ou associação na tabela do anexo III, a propaganda ou publicidade deve veicular a seguinte advertência: "(nome comercial do medicamento, ou, no caso dos medicamentos genéricos, a substância ativa) É UM MEDICAMENTO, SEU USO PODE TRAZER RISCOS PROCURE O MÉDICO E O FARMACÊUTICO. LEIA A BULA".

Entretanto, ao se iniciar a coleta de dados, foi percebida a ampla gama de infrações cometidas, em detrimento do preconizado pela legislação sanitária, em vigor.

Foi observado que não havia, simplesmente, uma apresentação tendenciosa de veicular a advertência do art. $22^{\circ}$, inciso VII. Também não havia uma preferência da propaganda para citar que o paciente procurasse 0 farmacêutico. O que ocorria (e ainda ocorre) é a violação à legislação.

Da revisão da literatura e observação das peças veiculadas, pode ser percebido que um risco sanitário iminente se apresentou em um quadro pernicioso à saúde do grande público da TV aberta, que habita essa região.

A população exposta ao risco é a do Distrito $\mathrm{Fe}-$ deral e "Entorno" (Águas Lindas, Céu Azul, Cristalina, Formosa, Valparaíso, Santo Antônio do Descoberto, Planaltina, Novo Gama, Cidade Ocidental, Mimoso, Luziânia e Padre Bernardo) que somada, apresenta-se em um quantitativo de aproximadamente 3,5 milhões de pessoas $(14,18)$.

Com a leitura meticulosa da resolução $\mathrm{n}^{\circ}$ 96/ RDC/2008/ANVISA/SVS/MS, foi estabelecido que a quantificação da análise, seria feita em razão do descumprimento de:

\section{Artigos infringidos:}

Artigo $4^{\circ}$ - Não é permitida a propaganda ou publicidade enganosa, abusiva elou indireta.

Artigo ${ }^{\circ}$

Parágrafo Único: No caso de propaganda ou pu- 
blicidade veiculada na televisão, quando as informações escritas não forem locucionadas, elas deverão ser exibidas pelo tempo suficiente à leitura.

Artigo $\mathbf{8}^{\circ}$ É vedado na propaganda ou publicidade de medicamentos:

I - estimular elou induzir o uso indiscriminado de medicamentos;

II - Sugerir ou estimular diagnósticos ao público em geral;

III - Incluir imagens de pessoas fazendo uso de medicamentos;

Artigo $22^{\circ}$ A propaganda ou publicidade (...), sendo exigido constar as seguintes informações:

VII - A advertência "SE PERSISTIREM OS SINTOMAS. O MÉDICO DEVERÁR SER CONSULTADO."

Artigo $23^{\circ}$ - A propaganda ou publicidade de medicamentos isentos de prescrição médica deve, também, veicular advertência relacionada à substância ativa do medicamento, conforme tabela do anexo III.

Parágrafo Único - No caso de não ser contemplada alguma substância ativa ou associação na tabela do Anexo III, a propaganda ou publicidade deve veicular a seguinte advertência: "(Nome comercial do medicamento ou, no caso de medicamentos genéricos, a substância ativa) É UM MEDICAMENTO. SEU USO PODE TRAZER RISCOS, PROCURE O MÉDICO E O FARMACÊUTICO. LEIA A BULA."

Artigo $24^{\circ}$ - A advertência a que se refere o Art. 23 deve ser contextualizada na peça publicitária, de maneira que seja pronunciada pelo personagem principal, quando veiculada na televisão.

I - A locução das advertências de que trata o caput deste artigo deve ser cadenciada, pausada e perfeitamente audivel.

II - Se a propaganda ou publicidade de televisão não apresentar personagem principal, as advertências devem observar os seguintes requisitos:

a) Após o término da mensagem publicitária, a advertência será exibida em cartela única, com fundo azul em letras brancas, de forma a permitir a perfeita legibilidade e visibilidade, permanecendo imóvel no vídeo;

b) A locução dever ser diferenciada, cadenciada, pausada e perfeitamente audivel.

Artigo $26^{\circ}$ Na propaganda ou publicidade de medicamentos isentos de prescrição é vedado:

III - apresentar nome, imagem, elou voz de pessoa leiga em medicina ou farmácia, cujas características sejam facilmente reconhecidas pelo público em razão de sua celebridade, afirmando ou sugerindo que utiliza o medicamento ou recomendando seu uso;
IV - Usar de linguagem direta ou indireta relacionando o uso de medicamentos a excessos etílicos ou gastronômicos; (17).

A análise das propagandas, sob a égide da resolução No 96 RDC/2008/ANVISA/SVS/MS, mostrou que, no período avaliado, $100 \%$ das peças publicitárias incorreram em infração à legislação.

Em média foram cometidas infrações em quatro (4) artigos da resolução por propaganda, e no total sete (7) artigos da RDC $\mathrm{N}^{\circ}$ 96/2008 foram ignorados nas propagandas amostradas. Estes resultados confirmam estudos anteriores nos quais foi verificado que todas as propagandas apresentaram alguma infração à legislação vigente $(8,19)$.

A Tabela 1 mostra a distribuição das propagandas captadas, de medicamentos industrializados isentos de prescrição, de acordo com as suas classes terapêuticas.

Tabela 1 - Propaganda de medicamentos de venda livre veiculada no Distrito Federal e Entorno, no período de março de 2012 a março de 2013, de acordo com suas classes terapêuticas $(\mathrm{n}=40)$.

\begin{tabular}{|c|c|c|}
\hline Classe terapêutica & Frequência & $\begin{array}{c}\text { Frequência } \\
\text { relativa (\%) }\end{array}$ \\
\hline $\begin{array}{l}\text { Analgésicos/ } \\
\text { Antipiréticos }\end{array}$ & 6 & $15 \%$ \\
\hline Antiinflamatórios & 4 & $10 \%$ \\
\hline Antimicóticos & 3 & $7,5 \%$ \\
\hline Antiácidos & 6 & $15 \%$ \\
\hline Antigripais & 6 & $15 \%$ \\
\hline $\begin{array}{l}\text { Purgativos (laxativos) } \\
\text { estimulantes }\end{array}$ & 1 & $2,5 \%$ \\
\hline Hepatoprotetores & 2 & $5,0 \%$ \\
\hline Expectorantes & 2 & $5,0 \%$ \\
\hline Fitoterápicos & 2 & $5,0 \%$ \\
\hline Antiflatulentos & 1 & $2,5 \%$ \\
\hline Antiespasmódicos & 1 & $2,5 \%$ \\
\hline Vitamínicos & 1 & $2,5 \%$ \\
\hline Complementos & 1 & $2,5 \%$ \\
\hline Outros & 4 & $10 \%$ \\
\hline
\end{tabular}

Os resultados encontrados se assemelham com os dados obtidos em outros trabalhos, com relação aos antiácidos (15\%) e antigripais (15\%) (20).

Em relação aos anti-inflamatórios (15\%), os resultados apresentaram menor índice. Porém, os dados ainda são preocupantes no que diz respeito ao risco gerado à saúde da população ao contribuir sobremaneira, para a automedicação. 
Se cotejados os dados, em relação aos anti-inflamatórios e analgésicos, com os obtidos em Goiás e no Rio Grande do Norte, pode ser observado que se confirmam os valores e no risco iminente à saúde pública, advindo do uso irracional dessas classes de medicamentos $(6,21)$.

Os resultados obtidos confirmaram os anti-inflamatórios entre os medicamentos que apresentam altos índices de publicidade (10\%), corroborando com os dados já obtidos por outros pesquisadores $(6,22)$.

Pode ser observado que, entre os mais altos índices de publicidade, nos resultados obtidos, os analgésicos estavam representados. Esses dados convalidaram de forma incontroversa, a incidência encontrada nos resultados de Bochner \& Souza (2008) e Tourinho et al.(2008) e reiteram a necessidade de controle das propagandas de medicamentos no Brasil $(23,24)$.

Ressalte-se, que desde a década de 90, os resultados obtidos são confirmados; analgésicos, antitérmicos e anti-inflamatórios são os mais consumidos em automedicação e o perfil da propaganda de medicamentos no Brasil, permanece o mesmo ou somente piora $(25,26)$, o que mostra a influência da propaganda de medicamentos neste consumo pois a evidência dos fatos somente vem se acumulando ao longo dos anos (26).

Os analgésicos, assim como outros fármacos ou substâncias consideradas "banais" pela população, se usados indevidamente, podem acarretar ao usuário, diversas consequências tais como: resistência bacteriana, reação de hipersensibilidade, dependência, sangramento digestivo, sintomas de retirada, aumento do risco para ocorrência de determinadas neoplasias' e falência hepática $(1,3,27)$.

Ora, os medicamentos não são mercadorias que possam ser oferecidas da mesma maneira que outros bens e serviços passíveis de regras do livre mercado (27).

A propaganda ao grande público, em TV aberta deve ser fiscalizada com rigor. Esse controle é

eticamente defensável, uma vez que, em questões básicas como a saúde pública, o Estado deve tomar frente e intervir, no compromisso de proteger a população contra qualquer possibilidade de ação que venha lhe causar danos $(27,28)$.

Considerando a classe terapêutica dos antigripais, que também apresentou alta incidência de propaganda $(15 \%)$, os resultados mostraram que a frequência de apresentação das propagandas é sazonal e que compreende o período entre abril e outubro de cada ano.

Em tempos de campanhas de vacinação contra a gripe, realizada pelo governo federal, para grupos específicos da população tais como: crianças, gestantes e idosos, pode ser inferido que as demais parcelas da população que não podem se vacinar no sistema priva- do de saúde ficam expostas ao duplo risco: o vírus e a propaganda abusiva.

Posto que, no período do ano citado, $100 \%$ das propagandas analisadas de antigripais descumpriram o artigo $8^{\circ}$, incisos I, II e III que tratam da estimulação e ou indução ao uso de medicamentos, sugestão e/ou estímulo de diagnóstico e a "inclusão de imagens de pessoas fazendo o uso de medicamentos" (Tabela 2).

Tabela 2 - Representação da distribuição da porcentagem do total de peças publicitárias $(n=40)$ que infringiram artigos da RDC $n^{\circ}$ 96/2008 para propaganda de medicamentos veiculadas no Distrito Federal e entorno (março de 2012 a março de 2013)

\begin{tabular}{|c|c|c|}
\hline Artigo & Frequência & Frequência relativa (\%) \\
\hline $4^{\circ}$ & 6 & $15 \%$ \\
\hline $6^{\circ}$ & 38 & $95 \%$ \\
\hline $8^{\circ}$ & 34 & $85 \%$ \\
\hline Art. $8^{\circ}, \mathrm{I}$ & 34 & $85 \%$ \\
\hline Art. $8^{\circ}, \mathrm{II}$ & 35 & $85 \%$ \\
\hline Art. $8^{\circ}, \mathrm{III}$ & 08 & $20 \%$ \\
\hline
\end{tabular}

Foi observado que a maioria das propagandas analisadas (95\%), infringiu o art. $6^{\circ}$ parágrafo úni$\mathrm{co}$, em desrespeito à norma e à saúde pública. Concernente às proibições impostas pelo art. $8^{\circ}$ e seus incisos I, II e III, em $85 \%$ dos resultados obtidos, a infração ocorreu.

Ademais, o fato de a publicidade apresentar claramente a indicação do medicamento, com a sugestão de um diagnóstico e automaticamente apresentar um tratamento correspondente sem, contudo evidenciar uma posologia, denota que além de praticar a automedicação, o indivíduo poderá fazer o uso do medicamento na dose que lhe convém e no horário que quiser $(28,29)$.

O estímulo, a indução ao uso, a sugestão de diagnóstico ao público e a inclusão de personagens "fazendo uso do medicamento" são uma constante nas propagandas (17).

Por exemplo, o antimicótico "V" (emissora R - 18/03/13 - 21h15min) - mostrou uma mulher que utilizava o medicamento (infração ao art. $8^{\circ}$ inciso III) e apresentava a frase "V resolve!". Além disso, não há tempo hábil, durante a veiculação, para que se possa ler a advertência do art. $23^{\circ}$ parágrafo único e art. $6^{\circ}$.

Estes dados mostram que a incidência de infrações aumentou, em relação ao trabalho de Melo et al. (2006) (8). Entretanto, são confirmados por Neto et al. (2012) (30). 
Resultados com altos índices de violação à legislação sanitária e, por conseguinte, à saúde coletiva, têm sido obtidos há vários anos $(14,20,22,26,31,32)$.

Esses estudos têm mostrado de forma enfática, que o modelo de fiscalização vigente e a forma de aplicação das penalidades previstas, assim como o valor das multas aplicadas não inibem as práticas abusivas do "marketing da dor" $(33,34,35,36)$.

É notório que o poder financeiro da propaganda abusiva tem sobrepujado o poder do Estado e, por conseguinte, do cidadão/ã por ele representado.

$\mathrm{Na}$ Tabela 3 está apresentada uma avaliação de informações que, imprescindivelmente, devem ser mostradas nas propagandas de medicamentos.

Como se pode observar na Tabela 3, as peças publicitárias não utilizam "repetições" para salientar informações que possam alertar o grande público a respeito do risco sanitário a que estão expostos.

Citam, minimamente, alguns dos cuidados/advertências que lhes são impostos pela legislação. Os resultados da obtidos no presente trabalho confirmam os estudos realizados em Minas Gerais (29).

A ausência de informações sobre os cuidados/ advertências caracteriza o produto farmacêutico como sendo totalmente seguro e eficaz, e eleva somente as características positivas do medicamento.

Entretanto, o nome comercial e as indicações terapêuticas dos medicamentos foram veiculados em todas as propagandas, exaustivamente. Seja por meio de repetições, por reiteradas vezes, seja pela pluralidade de atribuições, afinal, as repetições são o cartão de visita dos medicamentos (21).

A citação dos princípios ativos (Denominação Comum Brasileira - DCB e Denominação Comum Internacional - DCI) dos medicamentos nas propagandas, somente ocorreu em $10 \%$ das peças expostas na TV aberta.

Tabela 3 - Avaliação das informações inerentes ao medicamento presentes nas peças publicitárias $(n=40)$ veiculadas no Distrito Federal e entorno (março de 2012 a março de 2013)

\begin{tabular}{|l|c|c|}
\hline \multirow{2}{*}{ Informação terapêutica } & \multicolumn{2}{|c|}{$\begin{array}{c}\text { Presença nas peças } \\
\text { publicitárias }\end{array}$} \\
\cline { 2 - 3 } & Frequência & $\begin{array}{c}\text { Frequência } \\
\text { relativa (\%) }\end{array}$ \\
\hline Indicação terapêutica & 40 & 100 \\
\hline Nome comercial & 40 & 100 \\
\hline Princípio ativo (DCB/DCI) & 4 & 10 \\
\hline Contraindicações & 0 & 0 \\
\hline Reações adversas & 0 & 0 \\
\hline Cuidados/advertências & 4 & 10 \\
\hline Interações medicamentosas & 0 & 0 \\
\hline
\end{tabular}

Estes resultados sugerem que a omissão dessa informação é muito importante para não atrapalhar a divulgação da marca comercial.

Ora, se o público tiver a informação do princípio ativo (DCB/DCI) poderá ter o "direito" de escolher um medicamento de outra marca e/ou laboratório e/ou um medicamento genérico, com preço mais acessível à sua realidade sócio-econômica.

A não citação das contra-indicações dos medicamentos, nas propagandas analisadas, confirmam os estudos de Melo et al. (2006) e Nascimento (2009) $(8,11)$.

Os resultados reforçam ainda, ser prevalente a ausência de informações nas propagandas de medicamentos, que são informações que o consumidor deve saber antes de consumir tal medicamento, conforme corrobora Campos et al. (2012) (37).

A Figura 1 evidencia os resultados da análise dos artigos da resolução RDC/96/2008/ANVISA/SVS/MS que preconizam a apresentação de advertências nas peças publicitárias.

Figura 1. Propaganda de medicamentos industrializados isentos de prescrição, veiculadas no Distrito Federal e Entorno, que infringiram os artigos $22^{\circ}$, inciso VII, $23^{\circ}$, caput e $23^{\circ}$ parágrafo único da RDC 96/2008 (março de 2012 a março de 2013).

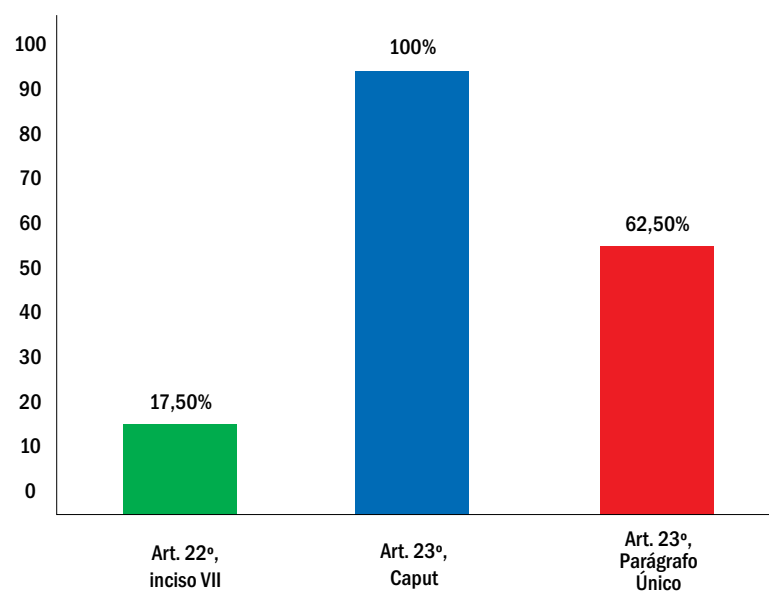

Pode ser observado que o art. $23^{\circ}$ caput foi ignorado em $100 \%$ das propagandas que deveriam veicular advertência relacionada à substância ativa do medicamento, conforme a tabela do anexo III da RDC N96/2008, em uma amostra de vinte e quatro (24) peças publicitárias que não cumpriram esse artigo. Esse resultado apresenta mais de trinta e três (33) pontos porcentuais acima dos valores obtidos em estudos no estado do Rio Grande do Norte (21).

Da amostra total de propagandas (40) que foram estudadas e analisadas, dezesseis (16) peças 
publicitárias deveriam ter apresentado advertência que consta no art. $23^{\circ}$ parágrafo único. Entretanto, apenas seis (6) propagandas cumpriram a determinação da legislação, portanto $62,5 \%$ das propagandas cometeram infração ao artigo. Estes resultados também são confirmados por estudos no nordeste do país $(21,30)$.

Na Figura 2 são apresentados os resultados da análise das peças publicitárias amostradas, com relação à locução de mensagem de advertência exigida no art. $24^{\circ}$ e da vedação preconizada no art. $26^{\circ}$ e seus incisos.

Das quarenta (40) peças publicitárias analisadas, a maioria (55\%) desrespeitou o art. $24^{\circ}$ incisos I e II alíneas a e b, em razão de que os medicamentos anunciados por elas apresentam alguma das substâncias da tabela do anexo III da RDC No 96/2008/ ANVISA, em sua composição. Assim, em caso do medicamento exposto na propaganda, tenha em sua composição ou como único princípio ativo a dipirona sódica, a advertência que deve ser veiculada, em acordo com a resolução RDC No 96/2008/ANVISA é: "Não use este medicamento durante a gravidez e em crianças menores de três meses de idade".

Da amostra estudada, vinte e duas (22) propagandas deveriam veicular advertências. Em 100\% dessas propagandas não houve, nem a exposição e nem a locução, de forma cadenciada, pausada e perfeitamente audível das advertências previstas na resolução No 96/2008/ ANVISA.

Não apresentar as advertências preceituadas em normas, demonstra de forma inequívoca, as pretensões apenas mercadológico-lucrativas das indústrias farmacêuticas que patrocinam as empresas de publicidade a veicularem os anúncios com infrações.

O valor encontrado nos resultados (55\%) mais que dobrou, em relação a outros estudos em que foram encontrados $20,5 \%$. Ressalte-se que durante aquele período de amostragem outra legislação vigorava $(30,31)$.

Este resultado é alarmante, sob o prisma do risco sanitário, sobretudo porque a RDC No 96/2008/ANVISA surgiu das necessidades de suplantar as fragilidades da RDC No 102/2000/ANVISA (17).

Portanto, parece ter sido de pequena monta o impacto causado pelas mudanças geradas a partir desta nova resolução, que com um texto mais extenso e detalhado pouco afetou o setor regulado.

O inciso IV do art. $26^{\circ}$ da RDC $\mathrm{N}^{\circ} 96 / 2008$, assim como todos os outros, trata-se de vedação na propaganda ou publicidade de medicamentos isentos de prescrição (MIP).
Figura 2. Distribuição percentual de propagandas de medicamentos veiculadas no Distrito Federal e Entorno, que infringiram os artigos a $24^{\circ}$ incisos I e II, e $26^{\circ}$ inciso IV da RDC 96/2008 (março de 2012 a março de 2013).

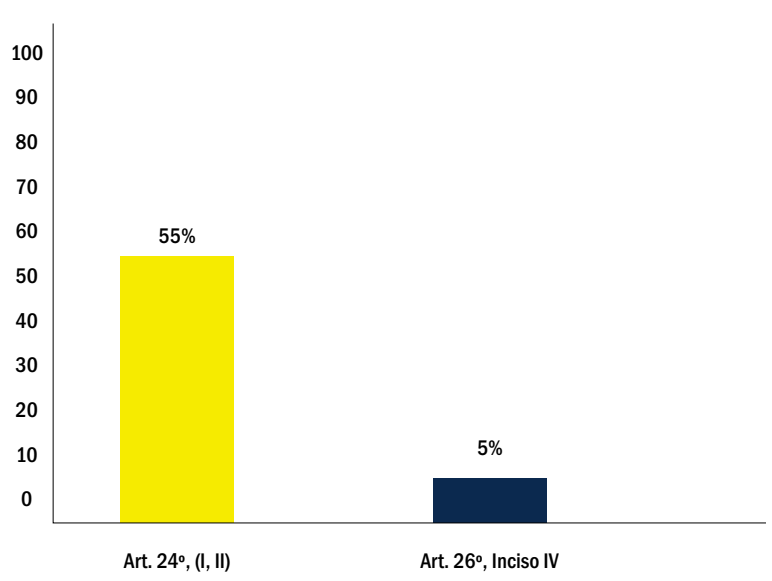

Assim sendo, mesmo que o resultado seja 5\% das peças amostradas, as consequências deletérias que podem advir do uso irresponsável de medicamentos MIP, em detrimento de hábitos de vida saudáveis, podem ser imensuráveis. Ou seja, pode-se comer e beber o que quiser, e o quanto desejar, pois, a solução está na medicação (medicamento $\mathrm{E}$, emissora $\mathrm{G}, 11 / 02 / 13$ - 13:15h).

Neste contexto, é que a função do farmacêutico torna-se peremptória. Este profissional deve estar com os seus conhecimentos atualizados para que possa atuar na orientação do paciente/consumidor de medicamentos e assim, corroborando com o profissional médico e ser um agente de interação entre o médico e o medicamento, o que o torna também um educador em saúde coletiva.

No que tange aos medicamentos (MIP), o profissional farmacêutico tem a oportunidade de orientar o paciente/consumidor ao uso correto e responsável de medicamentos em uma intervenção direta. E, portanto realizar efetivamente a Atenção Farmacêutica (AF) (38). Pois o propósito da AF é reduzir a morbimortalidade relacionada aos medicamentos e destarte o farmacêutico voltará a cumprir seu papel perante a sociedade, coresponsabilizando-se pelo bem estar do paciente/consumidor, assim como evitará prejuízos à sua qualidade de vida por problemas evitáveis, decorrente de uma terapia farmacológica (38).

Foi realizado o tratamento de análise descritiva dos resultados dos anúncios de medicamentos que não estão em conformidade com a RDC $\mathrm{N}^{\circ} 96 / 2008$, no que tange ao disposto nos art. $22^{\circ}$ inciso VII e $23^{\circ}$ parágrafo único, em relação às mensagens de advertência que devem ser apresentadas no final da peça publicitária; 
Mensagem 01 (médico): “SE PERSISTIREM OS SINTOMAS, O MÉDICO DEVERÁ SER CONSULTADO".

Mensagem 02 (médico e farmacêutico): "(nome comercial do medicamento, ou, no caso dos medicamentos genéricos, a substância ativa) É UM MEDICAMENTO, SEU USO PODE TRAZER RISCOS PROCURE O MÉDICO E O FARMACÊUTICO. LEIA A BULA".

Foi obtifo que $75 \%$ da amostra de anúncios expuseram a mensagem de advertência: "Se persistirem os sintomas, o médico deverá ser consultado".

A não conformidade reside no fato de que $33 \%$ destes anúncios deveriam ter apresentado, concomitantemente, a mensagem de advertência que orienta a procurar ambos os profissionais de saúde.

A mensagem de advertência 02 teve sua implementação legal por ocasião do advento da resolução $\mathrm{N}^{\circ}$ 96 RDC/2008/ANVISA/SVS/MS que revogou (expressamente) a RDC $\mathrm{N}^{\circ} 102 / 2000$ em sua integra, e ao que parece não restou clara ao setor regulado e seus prestadores de serviços midiáticos.

Ora, a resolução RDC No 102/2000 classificou os medicamentos em três categorias e regulamentou em detalhes a propaganda a ser aplicada a cada uma delas $(8,31,39)$. Contudo, a grande novidade dessa resolução foi a obrigatoriedade de se apresentar a advertência: "Se persistirem os sintomas, o médico deverá ser consultado" ao término da peça publicitária sobre propaganda de medicamentos MIP (22).

De sorte que o paciente/consumidor, que não for "perito" em legislação não poderá avaliar o motivo pelo qual se expõe uma advertência ou outra. E, por conseguinte, se existe maior credibilidade e/ou confiança ou não, na atuação de um ou de outro profissional, o que é contraproducente para um país que possui uma Política Nacional de Medicamentos (40).

O farmacêutico, no Brasil, sempre esteve inserido na intervenção da propaganda de medicamentos em sua prática profissional, a fim de prevenir a automedicação irresponsável. Uma vez que, o Decreto Federal $\mathrm{N}^{\circ} 20.377 / 1931$ que regulamentou o início da profissão farmacêutica no país, também introduziu as primeiras restrições legais para anúncios de medicamentos (41).

$\mathrm{Na}$ Tabela 4 estão apresentados os resultados que quantificam a participação das emissoras de TV aberta na coleta de dados que integram o conjunto amostral.

A emissora aqui intitulada "G" foi aquela que apresentou o maior valor percentual de veiculação de anúncios de medicamentos que cometeram infração à legislação sanitária específica. O valor díspar $(42,5 \%)$ obtido em relação às demais emissoras é numericamente o dobro do valor da emissora que apresentou o segundo maior valor (20\%).

Tabela 4 - Participação de cada canal das Emissoras de TV Aberta do Distrito Federal e Entorno na divulgação das propagandas de medicamentos que incorreram em infrações (março de 2012 a março de 2013).

\begin{tabular}{|ccc|}
\hline $\begin{array}{c}\text { Emissora } \\
\text { (Canal) }\end{array}$ & Frequência & $\begin{array}{c}\text { Frequência } \\
\text { relativa (\%) }\end{array}$ \\
\hline B & 8 & $20 \%$ \\
\hline RT & 4 & $10 \%$ \\
\hline R & 5 & $12,5 \%$ \\
G & 17 & $42,5 \%$ \\
\hline S & 6 & $15 \%$ \\
\hline
\end{tabular}

Este alto valor decorre do fato de que esta emissora veiculou um número muito significativo de peças publicitárias de medicamentos, no período amostral, e não que ela tenha obtido a maior audiência no período de estudo. Reitere-se que o interesse precípuo da discussão dos resultados seja demonstrar que em todos os canais monitorados a saúde pública esteve à mercê de interesses mercadológicos (14), pois considerável parcela da sociedade é diariamente exposta a apelos comerciais que possuem potencial para, em práticas específicas levar pessoas ao consumo desnecessário e desmedido de medicamentos (14).

Neste sentido, divulgar medicamentos como se fossem simples "mercadorias" para consumo é equivalente a incentivar a automedicação irresponsável que, agrava doenças e sintomas. Ou seja, promover a aquisição de medicamentos que podem ser ineficazes e/ou inadequados para aquela afecção, causa aumento dos custos ao sistema público de saúde, no que tange ao tratamento, internação e acompanhamento de intoxicados por medicamentos.

Pode-se depreender que, outros trabalhos que avaliaram propagandas de medicamentos isentos de prescrição, publicadas em vários tipos de mídia, também obtiveram dados que causam extrema preocupação (19).

Os resultados obtidos preocupam, por se tratarem de entre outros, ataques à saúde coletiva e, além disso; do autodiagnóstico, indução ao uso indiscriminado de medicamentos, resultados também encontrados no Rio Grande do Sul (42).

\section{CONCLUSÃO}

As infrações cometidas pelas peças de publicidade, veiculadas no DF e região do "entorno" parecem ter o objetivo de propagar a mensagem de que o alívio 
instantâneo dos sintomas se torne uma prioridade para o paciente/consumidor.

$\mathrm{O}$ uso indiscriminado e abusivo de medicamentos isentos de prescrição como alternativa para diminuir sintomas e promover uma melhoria imediata da saúde, é uma consequência das estratégias abusivas das propagandas infratoras da legislação sanitária.

$\mathrm{O}$ marketing farmacêutico utiliza com maior intensidade e quantidade a mídia televisiva, por ser a mais abrangente e promover um melhor retorno financeiro, por sua capacidade de alcance em todo o território nacional.

A obtenção de resultados com altos índices de infração contra vários artigos (art.; $23^{\circ}$ caput: $100 \%$ de infração; art. $24^{\circ}$ incisos, I e II: $55 \%$ de infração; art. $23^{\circ}$ parágrafo único: $33 \%$ de infração) da resolução RDC $n^{\circ}$ 96/2008/ANVISA, confirma que existe urgência na tomada de medidas rápidas e eficazes a respeito do complexo problema da publicidade de medicamentos no país.

O maior percentual de propagandas de MIP foi veiculado na emissora " $G$ " (42,5\%). Esta emissora de TV aberta cobra o maior valor para cada "segundo" de tempo de propaganda, no "horário nobre" (43).

Com a revisão da literatura pode-se concluir que, a indústria farmacêutica investe muito em propaganda/ publicidade e pouco em pesquisas para aumentar a segurança e a eficácia dos fármacos. Esta prática não favorece a saúde pública brasileira, pois, nos países em de- senvolvimento a maior parte do mercado farmacêutico está sob os auspícios de empresas privadas que praticam preços mais elevados para os medicamentos.

$\mathrm{O}$ alto percentual de infrações demonstra que o "setor regulado" é cônscio de que a propaganda influencia sobremaneira a prescrição e o consumo dos medicamentos, pois com o grande número de medicamentos com a mesma finalidade, o que decisivamente irá diferenciar será a divulgação midiática do produto farmacêutico.

A revisão da literatura confirma que o emprego inadequado de medicamentos pode originar doenças iatrogênicas, pois nenhum medicamento é inócuo ao organismo. Pode-se concluir que é premente a aplicação do mecanismo de anuência prévia das propagandas de medicamentos, que já é utilizado em diversos países desenvolvidos, para se efetivar o real controle sobre a informação que será disseminada à população e desta forma impedir a exposição ao risco sanitário. De forma que, não se pode olvidar que a promoção de saúde pública é dependente de diversos fatores, entre os quais; condições sanitárias adequadas, moradia ideal, alimentação suficiente e balanceada, água potável para ingestão.

Além de prescrição correta de medicamentos com a devida orientação médica, assim como uma orientação farmacêutica competente, fidedigna e adequada.

Por fim, a promoção de saúde pública, perpassa também por uma divulgação publicitária legítima, com informações que possam orientar e instruir o paciente/ consumidor e não que tenha a prerrogativa de vender a doença e a dor de forma mercadológica.

\section{REFERÊNCIAS}

1. Marques PE, Oliveira AG, Menezes GB. Quando o que cura passa a matar. Rev. Ciência Hoje. 2013. 51(302):18-23.

2. Araújo CP, Bochner R, Nascimento AC. Marcos legais da Propaganda de medicamentos: Avanços e retrocessos. Physis [on-line]; 2012. 22(1): 331-346.

3. Forner S, Silva MS, Brozozowski FS. Propaganda de medicamentos, automedicação e a ética farmacêutica: Uma tríade farmacêutica. [on-line]; Instituto Salus, 2012. [01 mar. 2013]; Disponível em: http://www.institutosalus.com/_arquivos/artigos/.pdf.

4. BRASIL Lei $n^{\circ}$ 5.991/1973. Dispõe sobre o controle sanitário do comércio de drogas, medicamentos, insumos farmacêuticos e correlatos, e dá outras providências. Diário Oficial da União 1973. [01 mar. 2013]; Disponível em: http:// www.planalto.gov. br/ccivil03/leis/L5991.htm.

5. Schenkel EP, Mengue SS, Petrovick PR. (org) Cuidados com os medicamentos. $5^{\text {a }}$ ed. rev., Florianópolis: Ed. da UFSC, 2012.
6. Zampieri ALTC et al. Monitoração da propaganda de medicamentos: Principais irregularidades que podem levar o Profissional Odontólogo à prescrição induzida de analgésicos e anti-inflamatórios Rev. Eletrônica de Farmácia. 2005. 2(supl.2): 194-197. Disponível em: http://www.revistas.ufg.br.

7. Paulo GL, Zanine AC. Automedicação no Brasil. Rev. Ass. Med. Brasil.1998. 34(2): 69-75.

8. Melo DO, Ribeiro E, Storpirtis S. A importância e a história dos estudos de utilização de medicamentos. Rev. Bras. Cienc. Farm. 2006. 42(4): 475-485.

9. MINISTÉRIO DA SAÚDE, Fundação Oswaldo Cruz/Centro da Informação Científica e Tecnológica/Sistema Nacional de Informação teórico-Farmacológica. Casos Registrados de Intoxicação Humana, de Intoxicação Animal e de Solicitação de Informação por Agente Tóxico. [24 mar. 2013]; Brasil, 2010. Disponível em: http://www.fiocruz.br/sinitox. 
10. Agência Brasil. "T será recolhido". Jornal Correio Braziliense, 22/05/2013. [04 jun. 2013]; Disponível em: http://www.correiobraziliense.com.br.

11. Nascimento AC. Propaganda de medicamentos no Brasil. É possível regular? Ciênc. saúde colet. 2009, 14(3): 869-877.

12. Jornal O Globo. Pesquisa realizada pela Promotoria de Defesa do Consumidor-PROCON - São Paulo. [on-line]; 2007, p. 38.

13. Nascimento AC. Propaganda de medicamentos para grande público: parâmetros conceituais de uma prática produtora de risco. Ciênc. saúde colet. 2010. 15(3): 3423-3431.

14. Ramalho V. Tecnologias discursivas na propaganda de medicamentos. Discurso e Sociedade. 2010. 4(3): 507-537.

15. Angell M. A verdade sobre os laboratórios farmacêuticos; como somos enganados e o que podemos fazer a respeito. Trad. Waldéa Barcellos. Rio de Janeiro: Ed. Record, 2009.

16. Rang HP, Dale MM, Ritter JM, Moore PK. Farmacologia. Tradução: Patrícia Lydie Voeux, Antônio José Magalhães da Silva Moreira. Rio de Janeiro: Elsevier, 2009.

17. BRASIL. Agência Nacional de Vigilância Sanitária - ANVISA. Resolução de Diretoria Colegiada. № 96, de 17 de dezembro de 2008. Dispõe sobre a propaganda, publicidade, informação e outras práticas cujo objetivo seja a divulgação ou promoção comercial de medicamentos. [10 abr. 2013]; Disponível em: http:// www.anvisa.gov.br/propaganda/rde/rdc_96_2008_consolidada. pdf.

18. IBGE. Instituto Brasileiro de Geografia e Estatística. População habitante/Estados/Cidades. [11 mai. 2013]; Disponível em: http://www.ibge.gov.br

19. Wzorek LF, Correr CJ, Trindade ACB, Pontarolo R. Analysis of medicine advertisement produced in Brazil. 2007. Pharmacy Pratice, 5(3):105-108

20. Luchessi AD, Marçal BF, Araújo GF, Uliana LZ, Rocha MRG; Pinto TJA. Monitoração de propaganda e publicidade de medicamentos: âmbito de São Paulo. Rev. Bras. Cienc. Farm. 2005. 41(3): 346-349.

21. Batista, AM. Carvalho MCRD. Avaliação da propaganda de medicamentos veiculada em emissoras de rádio. 2013. Ciênc. saúde colet. 18(2): 553-561.

22. Nascimento AC. "Ao persistirem os sintomas, o médico deverá ser consultado." Isto é regulação? São Paulo: Sobravime, 2005. $151 \mathrm{p}$.

23. Bochner R, Souza VMFA. Panorama das Intoxicações e Envenenamentos Registrados no Brasil pelo Sistema Nacional de Informações Tóxico-Farmacológicas (SINITOX). Rev. Racine. 2008. 18(106):44-58.

24. Tourinho FS, Bucaretchi F, Stephan C, Cordeiro R. Home medicine chests and their relationship with self-medication in children and adolescents. J. Pediatr. (Rio J.). 2008. 84(5): 416-422.

25. Vilarino JF, Soares IC, Silveira CM, Rödel APP, Bortoli R, Lemos RR. Perfil da automedicação em município do sul do Brasil. Rev. Saúde Pública. 1998. 32(1): 43-49.

26. Soares JCRS, Quando o anúncio é bom, todo mundo compra: O projeto Monitoração da propaganda de medicamentos no Brasil. Ciênc. saúde colet. 2008. 13(supl. 0): 641-649.

27. Fagundes MJD, Soares MGA, Diniz NM, Pires JR, Garrafa V. Análise bioética da propaganda e publicidade de medicamentos. Ciênc. saúde colet. 2007. 12(1):221-229.
28. Garrafa V, Porto D. Intervention bioethics: a proposal for peripheral countries in a context of power and injustice. Bioethics. 2003. 17 (5-6): 399-416.

29. Azevedo GS, Pereira OAV. Análise da publicidade das propagandas de medicamentos veiculadas em emissoras de televisão. Rev. Farm. Cienc. 2010.1(1): 3-15.

30. Neto LSC. Cortez ACL. Santos DB, Sousa GC. Análise das propagandas de medicamentos veiculadas em emissoras de televisão e sua concordância com a legislação vigente. Rev. Piauiense Saúde - Northeeast Brazilian Health Journal. 2012. 1(2): 34-40.

31. Nascimento AC. Propaganda de medicamentos. É possível regular? [Tese]. Rio de Janeiro: Instituto de Medicina Social, Universidade do Estado do Rio de Janeiro; 2007.

32. Vitor RS, Lopes CP, Menezes HS, Kerkhoff CE. Padrão de consumo de medicamentos sem prescrição médica na cidade de Porto Alegre, RS. 2008. Ciênc. saúde colet.13:737-743.

33. Jesus PRC. Qual o papel das palavras na propaganda de medicamentos? Rev. Acad. Grupo Comunicacional de São Bernardo. [on-line]. Universidade Metodista de São Paulo. São Paulo: 2004. [20 set. 2013]; Disponível em: http://www.metodista.br/ unesco/GCSB/index.htm.

34. Jesus PRC. As palavras e seus efeitos na propaganda de medicamentos no Brasil. Uma análise semiótica, midiática e ética. [on-line]. 2005. [13 set. 2013]; Disponível em: http://www.paularenata.com/downloads/palavras_efeitos.pdf.

35. Jesus PRC. As mensagens persuasivas dos medicamentos. Verdade ou mentira? In: UNESCOM - Congresso Multidisciplinar de Comunicação para o Desenvolvimento Regional São Bernardo do Campo - São Paulo: Universidade Metodista de São Paulo; 2006.

36. Jesus PRC. Propaganda de Medicamentos na Mídia de Massa: Celebridades e Automedicação. caderno.com / [Publicação do] Curso de Comunicação Social da Universidade Municipal de São Caetano do Sul. 2009. 4(2): 39-47.

37. Campos CMT, Alexandri, AM, Foppa AA, Cunha HP, Scherer MLS, Rover MRM.; Zannin M. Atividades de educação em saúde envolvendo o uso racional de medicamentos. Escola de educação básica José Boiteux, Município de Florianópolis, SC. Infarma - Rev. Pharmacia Brasileira. 2012. 24(4/6): 36-41.

38. Vieira FS. Possibilidades de contribuição de farmacêutico para a promoção da saúde. Ciênc. saúde colet. 2007.12(1): 213-220.

39. BRASIL. Agência Nacional de Vigilância Sanitária - ANVISA. Resolução de Diretoria Colegiada. $N^{\circ} 102$, de 30 de novembro de 2000. [10 dez. 2013]; Disponível em: http://www.anvisa.gov.br/ legis/resol/2000/102 00rdc.htm.

40. BRASIL, Portaria ${ }^{\circ} 3.916$ / GM de 30 de Outubro de 1998 Aprova a Política Nacional de Medicamentos. Diário Oficial da União, 10 março de 1998. [30 jun. 2013]; Disponível em: http:// www.in.gov.br.

41. BRASIL, Decreto-Lei ${ }^{\circ} 20.377$, de 8 de setembro de 1931. Resolve aprovar o regulamento anexo para o exercício da profissão Farmacêutica no Brasil. Conselho Federal de Farmácia. [16 dez. 2013]; Disponível em: http://www.cff.org.br.

42. Silva BR, Corte TWF. A propaganda de medicamentos e sua adequação conforme a RDC 96/2008. Pontifícia Universidade Católica do Rio Grande do Sul. 2009. Rev. Graduação. [on-line]. 2(2). [21 ago. 2013]; Disponível em: http://www.pucrs.edu.br/ graduacao/monografias.

43. Bueno E, Taitelbaum P. Vendendo saúde - A história da propaganda de medicamentos no Brasil. Brasília: ANVISA, 2008. 